\title{
Ecofriendly synthesis Of Silver Nanoparticles Using ethno medicinal plant leaf extract (Jasminum Auriculatum ) and their Antibacterial properties
}

\author{
S. Balasubramanian ${ }^{1, a^{*}}$, U. Jeyapaul ${ }^{2, b}$, S.Mary Jelastin Kala ${ }^{3, c}$ \\ ${ }^{1 *}$ Chemistry Research Centre, St.Xaviers College , Palayamkottai , Tirunelveli-627002, India. \\ ${ }^{1 *}$ Assistant Professor, Department of Chemistry, A.R. College of Engineering \& Technology, \\ Kadayam , Tirunelveli-627423, India. \\ ${ }^{2,3}$ Assistant Professor, Department of Chemistry, St.Xaviers College, Palayamkottai, \\ Tirunelveli-627002, India . \\ a*bensosurya@yahoo.com ,bjpaulser25@gmail.com ,'kalaclement97@gmail.com \\ ${ }^{*}$ Corresponding author: Email id: bensosurya@yahoo.com
}

Key words : Silver nanoparticles, FTIR spectra, XRD, SEM, EDX, Antibacterial activity.

\begin{abstract}
The present investigation, we describe a cost effective biofabrication of silver nanoparticles using jasminum auriculatum leaf extract. The aqueous leaf extract of jasminum auriculatum are used as reducing agent and capping agent in silver nanoparticles synthesis. The biofabricated silver nanoparticles were characterized by UV-Visible spectrophotometer, X-Ray Diffraction, FTIR spectra and SEM with EDX analysis. FTIR studies revealed that the functional group responsible for silver reduction were found to be jasminol and triterpinoid compounds present in leaf extract. XRD analysis showed that prepared silver nanoparticles are crystalline in nature with an average diameter of 15-20 $\mathrm{nm}$. The prepared silver nanoparticles have been evaluated in vitro for antibacterial activities and found to have higher antibacterial activities.
\end{abstract}

\section{INTRODUCTION}

Nanotechnologies are among the fastest growing areas of scientific research and have important applications in a wide variety of fields. Nanomaterials have different physical, chemical and biological properties than their macro scaled counterparts [1,2]. Nanoparticles are commonly synthesized using two steps: top-down and bottom-up [3]. In top-down process, the bulk materials are gradually broken down to nanosized materials. In bottom-up process, atoms or molecules are assembled to molecular structures in nanometer scale[4]. In bottom-up silver nanoparticles are synthesized by various chemical, physical and biological methods. Biological methods for the green synthesis of nanoparticles are cost effective and eco- friendly compared to physical and chemical method[5]. Plants are relatively safe, easily available and affordable to the masses. Green synthesis of nanoparticles has been achieved using environmentally acceptable plant extract and eco-friendly reducing and capping agents. Uptill now, biological methods of nanoparticle synthesis using plants and plant extract such as Azadirachta Indica [6], Euphorbia hirta[7], Boswellia ovalifoliata and Shorea tumbuggaia[8] have been proven to be eco-friendly alternatives to chemical and physical methods. The use of plants for the synthesis of nanoparticles does not require high energy, temperatures and it is easily scaled up for large scale synthesis[9]. However ethno medicinal potential value of many plants along with their role in synthesis of nanoparticles is yet to be studied in detail.

Noble nanomaterials have been synthesized using a variety of methods, including hard template, bio-reduction and solution phase synthesis[10,11,12]. Among noble metal nanomaterials, Silver nanoparticles have received considerable attention due to their attractive physicochemical properties[13]. Silver nanoparticles exhibit strong toxicity in various chemical forms to a wide range of microorganisms and have shown to be a promising antimicrobial material[14,15]. Silver nanoparticles have been used as a healing and antibacterial agent for thousands of years[16]. 
Jasminum auriculatum is used as Ethno medicinal plants in India. It is belonging to Oleaceae family and commonly known as Juhi. It is a stunning, small climbing bushy plant with simple ovate dark green small leaves and powdery satin white flowers[17]. It is found in India, Nepal, Sri Lanka, Bhutan, and the Andaman Islands[18,19] .

Jasminum auriculatum leaves contain bioactive constituents such as Lupeol, Epilupeol, Hentriacontane, n-triacontanol, Jasminol, malvali cacid, $\mathrm{C}_{20}-\mathrm{C}_{34}$ Hydrocarbons, iso- $\mathrm{C}_{26}, \mathrm{C}_{28}, \mathrm{C}_{30}$ wax alcohols, palmitic acid, stearic acid, linolenic acid ,linoleic acid, xylitol, inositol, sorbitol, Jasmone, D-mannitol , Cis-Jasmone, and dihydrojasmone [20]. The plant is used as Wound Healing[21], Antilithiatic[22], immunostimulatory activity [23].

Based on the importance of green synthesis of silver nanoparticles from leaf extract[24], Herein we report the biofabrication of silver nanoparticles using Jasminum Auriculatum Leaf Extract .The obtained silver nanoparticles were characterized by UV-Visible spectroscopy, FTIR spectra analysis, EDX analysis and SEM analysis. The antibacterial activity of the prepared sample was evaluated against two Gram negative and two Gram positive pathogenic bacteria by using disc diffusion method.

\section{MATERIALS AND METHODS}

\subsection{Collection of plant samples}

Jasminum auriculatum plants were collected from Munnirpallam, Tirunelveli district, Tamilnadu, India. The plants leaves were thoroughly washed thrice with tap water and then with sterile double distilled water to remove dust particles and dried using filter paper.

\subsection{Preparation of aqueous plants leaf extracts}

$10 \mathrm{gm}$ of the dried fresh leaves were boiled well with $100 \mathrm{ml}$ of double-distilled water at $60^{\circ} \mathrm{C}$ for $30 \mathrm{~min}$. After boiling, the extract was cooled and then filtered through Whatman No.1 filter paper. Collect the supernatant and stored at $4^{\circ} \mathrm{C}$ for further nanoparticles synthesis process.

\subsection{Synthesis of silver nanoparticles}

$1 \mathrm{mM}$ aqueous solution of Silver nitrate $\left(\mathrm{AgNO}_{3}\right)$ was prepared by using distilled water and $\mathrm{AgNO}_{3} .10 \mathrm{ml}$ of Jasminum auriculatum leaf extract are added to $90 \mathrm{ml}$ of $1 \mathrm{mM}$ silver nitrate solution in $100 \mathrm{ml}$ beaker and kept at room temperature. After1 hours, colour of the solution was changed from yellow to reddish brown due to synthesis of silver nanoparticles.

\section{CHARACTERIZATION STUDIES}

The biosynthesized silver nanoparticles were characterized by the following methods:

\subsection{Visual Observation:}

A change of colour from pale yellow to reddish brown was observed in the solution after visible irradiation.

\subsection{UV Spectrophotometric analysis:}

The silver nanoparticles were confirmed by the spectral analysis. The UV spectra of the biosynthesized silver nanoparticles were recorded using Lambda 35, Perkin Elmer UV Spectrophotometer by continuous scanning from $200 \mathrm{~nm}$ to $900 \mathrm{~nm}$ and the leaf powder extract was used as the reference for the baseline correction.

\subsection{Fourier Transform Infra Red Spectroscopy Analysis:}

FTIR analysis was carried out to determine the functional groups present in Jasminum auriculatum leaf extract and their possible involvement in the synthesis of silver nanoparticles. FTIR analysis were carried using a FTIR SHIMADZU 8400S instrument with a wavelength range of 4000 to $400 \mathrm{~nm}$ where the samples were incorporated with $\mathrm{KBr}$ pellets to acquire the spectra. The results were compared for shift in functional peaks. 


\subsection{XRD analysis :}

The obtained silver nanoparticles was purified by repeated centrifugation at 10,000 rpm for 20 min. The purified silver nanoparticles are dried. The dry powder of silver nanoparticles were characterized by Bruker XRD machine (D8 Advance ECO XRD System with SSD160 1 D Detector). The data was collected in the $2 \Theta$ range. The crystalline domain size was calculated from the width of XRD peaks using Dabye-Scherrer's equation, $D=K \lambda / \beta \operatorname{Cos} \Theta$.

Where, $\mathrm{D}=$ average crystalline domain size; $\mathrm{K}=0.94, \lambda=$ wave length of $\mathrm{X} \operatorname{ray}\left(\mathrm{A}^{0}\right), \Theta$ is the diffraction angle and $\beta$ is the Full Width at Half Maximum (FWHM) in rad.

\subsection{SEM \& EDX Analysis :}

The surface morphology of silver nanoparticles was examined using a scanning electron microscopy (Carl Zeiss EVO 18). The elemental composition of the synthesized silver nanoparticles was analyzed using Energy Dispersive X-Ray Spectrometer (Quantax 200 with X-Flash-Bruker).

\subsection{Antibacterial activity :}

The antimicrobial study of silver nanoparticles was estimated against pathogenic bacteria such as Enterococcus faecalis, Staphylococcus aureus (gram- positive bacteria), Pseudomonas aeruginosa, E. coli (gram-negative bacteria) by disc diffusion method[25]. The bacterial cultures were grown in Brain Heart Infusion liquid medium at $37{ }^{\circ} \mathrm{C}$. After $12 \mathrm{hrs}$ of growth, each microorganism, at a concentration of $1 \times 10^{6}$ cells $/ \mathrm{ml}$ equivalent to $0.5 \mathrm{Mc}$ Farland Standard was spread on the surface of Mueller-Hinton agar plates. The dilutions were made in sterile low glucose Nutrient broth. Test pathogens were spread on the test plates- Muller Hinton agar for bacteria. The synthesized silver nanoparticles and positive control ( $5 \mu \mathrm{g}$ of ciprofloxacin per disc) were loaded onto $6 \mathrm{~mm}$ diameter sterile discs and placed in the plates respectively. After $24 \mathrm{hrs}$ of incubation the zone of inhibition ( $\mathrm{mm}$ in diameter) was measured and taken as the activity against the test pathogen.

\section{RESULTS AND DISCUSSION}

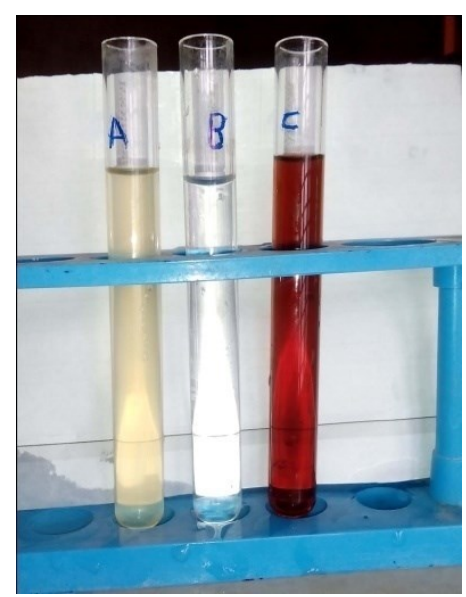

Fig-1 Colour change indicating formation of Ag NPS

Fig-1: solution of (A)Jasminum auriculatum leaf extract (B) $1 \mathrm{mM} \mathrm{AgNO}_{3}$ Solution without leaf extract (c) $1 \mathrm{mM} \mathrm{AgNO}_{3}$ Solution with leaf extract after $1 \mathrm{hrs}$

\subsection{UV- Visible Spectroscopy:}

The nanoparticles were primarily characterized by UV-Vis spectroscopy, which was provided to very useful in technique for the analysis of nano particles. A well defined peak at 417 $\mathrm{nm}$ exhibited by the nano metallic silver particles and broadening of peak indicated that the particles are polydispersed[26,27]. The colour change from the colourless to reddish brown due to the excitation of free electrons in the nanoparticles[28]. It confirm the successful synthesis of silver nanoparticles. The absorption spectrum of silver nanoparticles from Jasminum auriculatum leaf extract are shown in fig. 2 . 


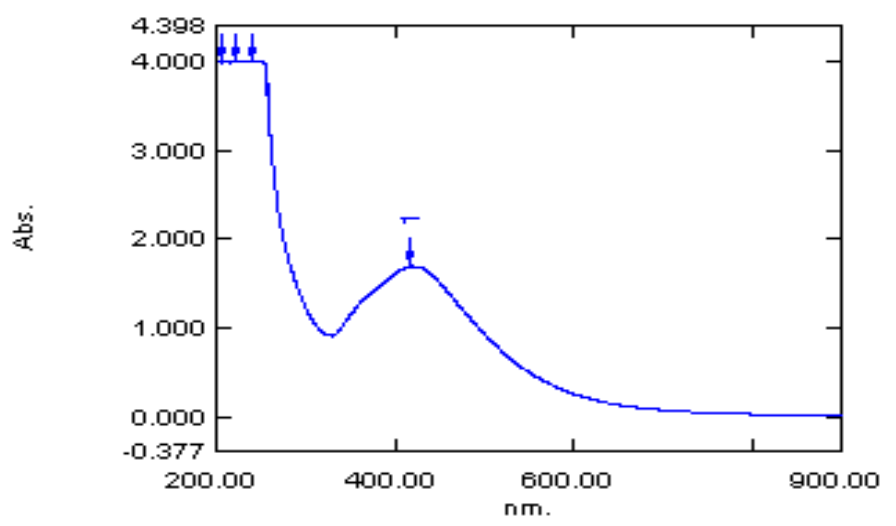

Fig -2 : UV Spectral analysis of Ag NPs synthesized from Jasminum auriculatum leaf extract

\subsection{FTIR analysis:}

FT-IR measurement was carried out to identify the possible bio molecules responsible for capping and reducing agent for the silver nanoparticles synthesized by jasminum auriculatum leaf extract. The peak at $3437.01 \mathrm{~cm}^{-1}$ which is corresponds to $\mathrm{O}-\mathrm{H}$ stretching of phenols (jasminol) and alcohols and N-H stretching of amines(alkaloids). The peak at $2360.98 \mathrm{~cm}^{-1}$ corresponds to $\mathrm{C} \equiv \mathrm{N}$ stretching of nitriles and $\mathrm{C} \equiv \mathrm{C}$ stretching of alkynes. The peak at $2075.05 \mathrm{~cm}^{-1}$ corresponds to $\mathrm{C} \equiv \mathrm{N}$ stretching of nitriles and stretching of $\mathrm{CO}_{2}$ molecule, the peak at $1640.08 \mathrm{~cm}^{-1}$ corresponds to $\mathrm{C}=\mathrm{O}$ stretching of aromatic ester and enolic ketones (triterpinoids) and $\mathrm{C}=\mathrm{C}$ stretching of alkenes, the peak at $1334 \mathrm{~cm}^{-1}$ corresponds to $\mathrm{S}=\mathrm{O}$ stretching of sulfone, peaks at $671.89 \mathrm{~cm}^{-1}$ corresponds to $\mathrm{C}-\mathrm{Cl}$ stretching of aryl halides. These bio molecules reduced $\mathrm{Ag}^{+}$to $\mathrm{Ag}$ as well as stabilizing silver nanoparticles. Fig.3. shows FTIR spectrum of synthesized silver nanoparticles from jasminum auriculatum leaf extract.

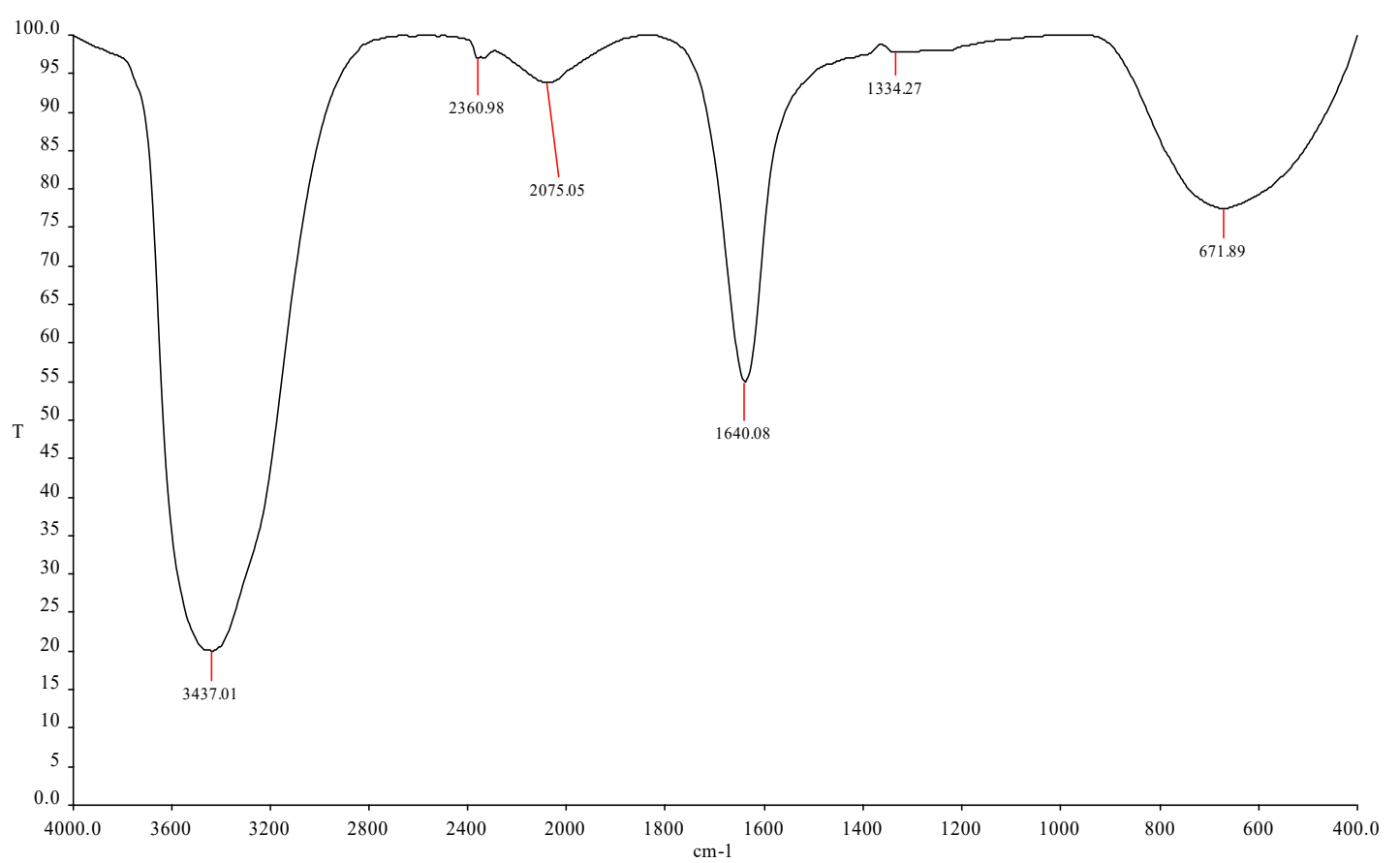

Fig - 3 : FT-IR Spectra of Ag NPs synthesized from jasminum auriculatum leaf extract

\subsection{XRD Analysis:}

The XRD spectrum (Fig.4.) has four peaks at $2 \theta$ values of $37.96^{\circ}, 44.10^{\circ}, 64.36^{\circ}$ and $77.30^{\circ}$ corresponding to (111),(200),(220) and (311) planes of silver respectively. The obtained data was matched with the standard powder diffraction card of JCPDS silver file No.04-0783. The XRD study confirms that the resultant particles are face centered, cubic symmetry of silver nanoparticles. The high intense peak for FCC materials is generally (111) reflection, which is observed in the 
sample. The diffraction peaks are broad which indicate that the crystallite size is very small [29]. The average grain size of the silver nanoparticles formed in the process was calculated from the Debye-Scherrer equation and the mean size of the particle was $15-20 \mathrm{~nm}$.

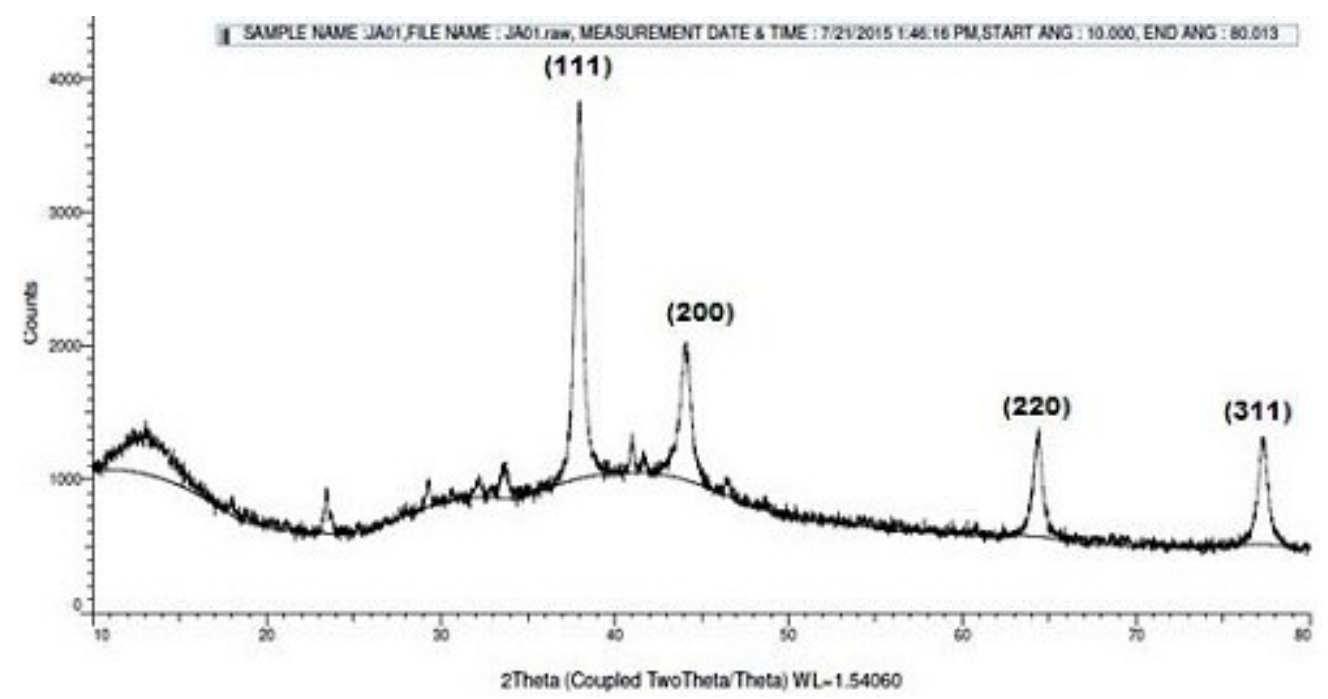

Fig-4.: XRD patterns of silver nanoparticles using jasminum auriculatum leaf extract

\subsection{SEM and EDX analysis:}
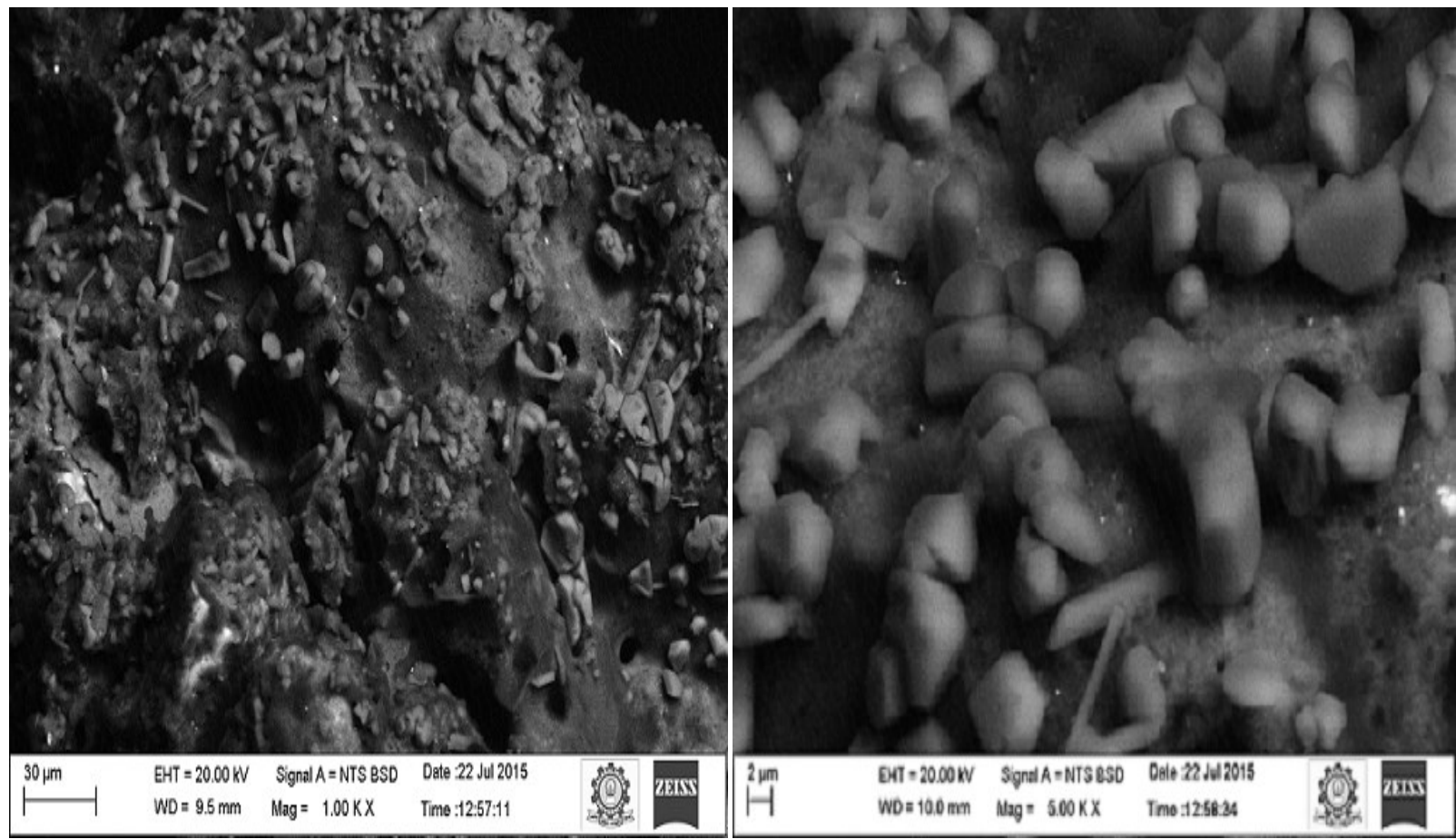

Fig -5.:SEM image of Ag NPs using jasminum auriculatum leaf extract

The morphological studies of silver nanoparticles was investigated using scanning electron microscopy (SEM). Fig.5. shows that the morphology of biosynthesized silver nanoparticles. SEM image (Fig.5.) revealed that biosynthesized silver nanoparticles from jasminum auriculatum leaf extract, are exhibited in rod, spherical, triangle and hexagonal shapes (Fig.5.) 


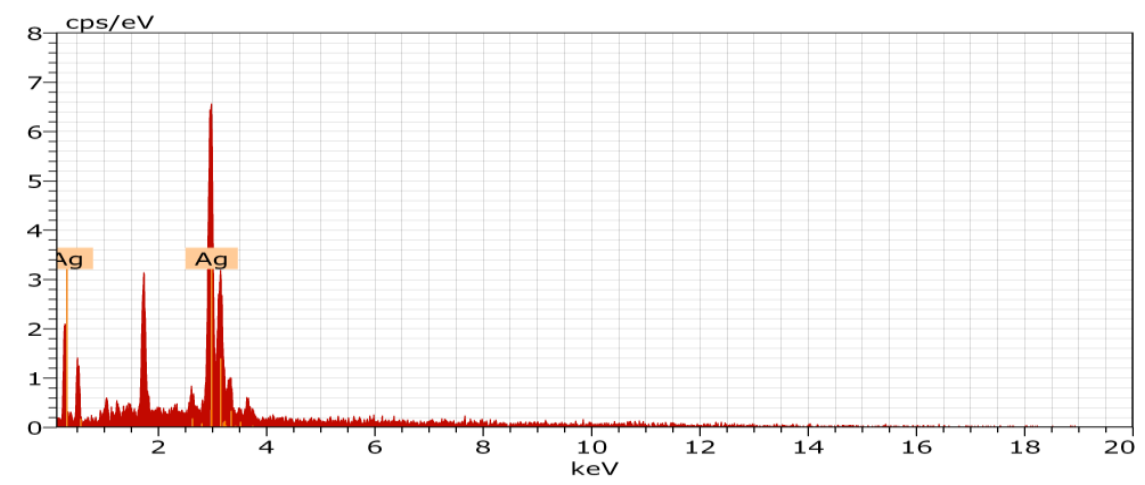

Fig-6 : EDX image of Ag nanoparticles using jasminum auriculatum leaf extract

The results of energy-dispersive X-ray spectroscopy (EDX) analysis are shown in Fig. 6. It is confirmed that the significant presence of elemental silver, which indicates bio reduction of silver ion to elemental silver. The strong signal in the silver region was observed at $3 \mathrm{keV}$ for silver nanoparticles due to the Surface Plasmon Resonance [30].

\subsection{Anti bacterial Activity:}

Antibacterial activity of silver nanoparticles is investigated against Enterococcus faecalis, Staphylococcus aureus (gram-positive ), Pseudomonas aeruginosa, E. coli (gram-negative) by disc diffusion method[31,32] are shown in Fig.8.
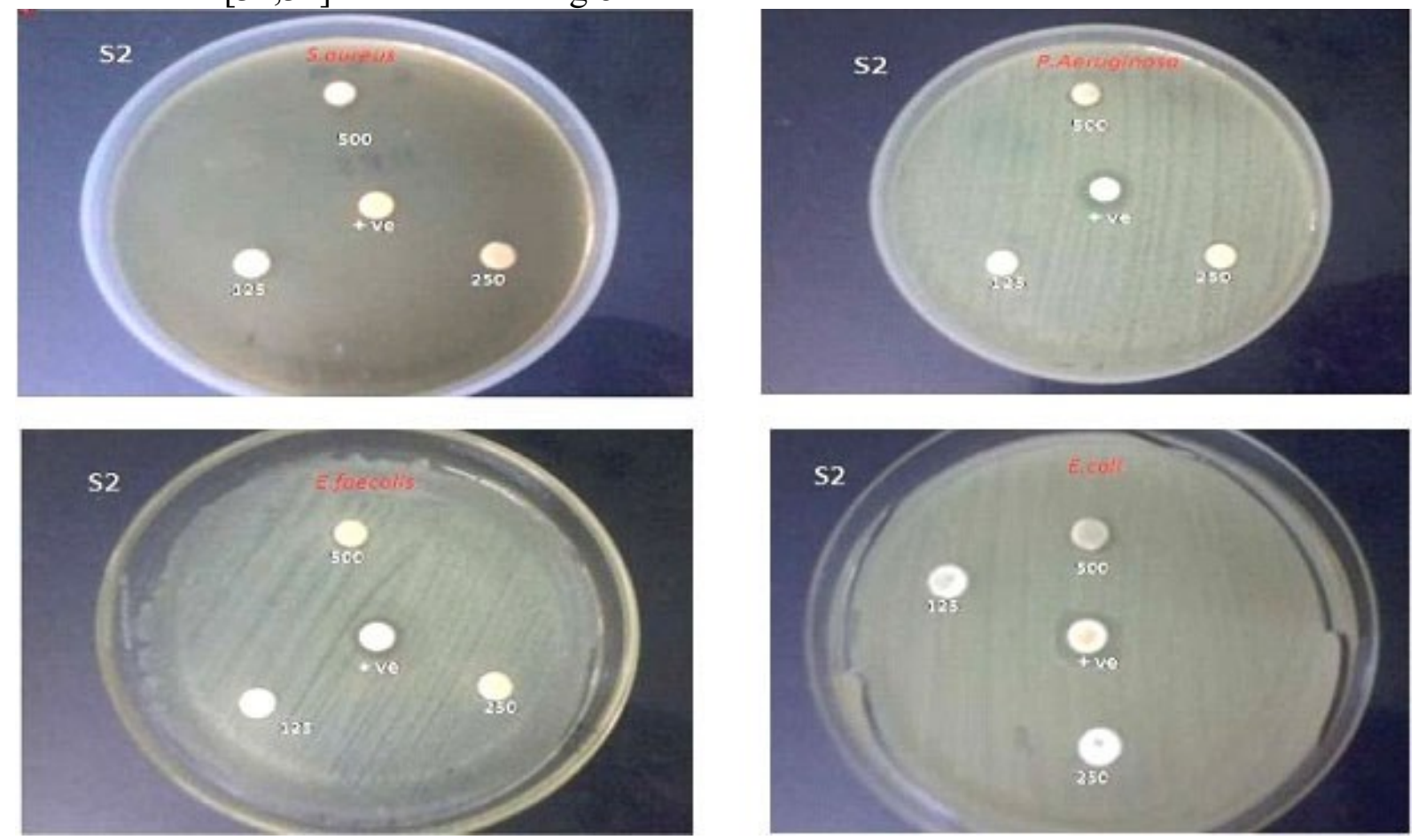

Fig - 8 : Antibacterial activity of Ag NPs using jasminum auriculatm extract against human pathogens

The diameter of inhibition zones $(\mathrm{mm})$ around each well with silver nanoparticles solution are represented in Table.1. The table.1. shows that the zone of inhibition (ZOI) was increased when increasing the concentration of silver nanoparticles. The maximum antibacterial activity in $500 \mu \mathrm{g} / \mathrm{ml}$ concentration of the synthesized silver nanoparticles was $12 \mathrm{~mm}$ for P. aeruginosa, 14 $\mathrm{mm}$ for E. coli, $12 \mathrm{~mm}$ for S. aureus and $11 \mathrm{~mm}$ for E. faecalis receptively. The silver nanoparticles synthesized by jasminum auriculatum leaf extract are found to have highest antibacterial activity against E. coli $(14 \mathrm{~mm})$ respectively and the lesser antimicrobial activity of silver nanoparticles is found against $\mathrm{E}$. faecalis $(11 \mathrm{~mm})$. The antibacterial activity of silver nanoparticles studies confirmed that the silver nanoparticles synthesized by jasminum auriculatum leaf extract exhibited good antibacterial potential against gram-positive and gram-negative bacterial strains. 


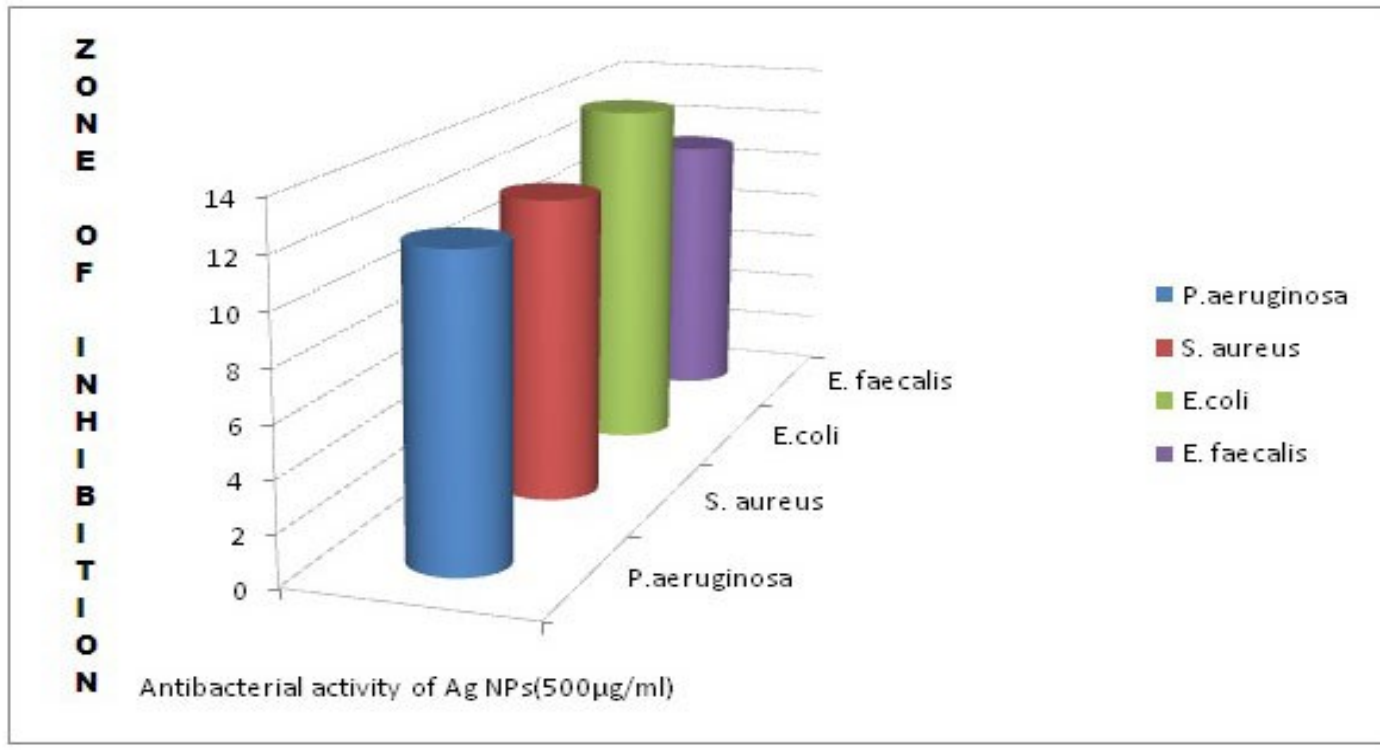

Table - 1

\begin{tabular}{|c|c|c|c|c|c|}
\hline \multirow{2}{*}{$\begin{array}{c}\text { Serial. } \\
\text { No }\end{array}$} & \multicolumn{5}{|c|}{ Zone of inhibition of Ag NPS ( mm) } \\
\cline { 2 - 6 } & Strains & $\begin{array}{c}\text { Pseudomonas } \\
\text { aeruginosa }\end{array}$ & $\begin{array}{c}\text { Staphylococcus } \\
\text { aureus }\end{array}$ & E.coli & $\begin{array}{c}\text { Enterococcus } \\
\text { faecalis }\end{array}$ \\
\cline { 2 - 6 } & $\mu \mathrm{g} / \mathrm{ml}$ & & 12 & 14 & 11 \\
\hline 1 & 500 & 12 & - & 11 & - \\
\hline 2 & 250 & 10 & - & - & - \\
\hline 3 & 125 & - & \multicolumn{4}{c}{} \\
\hline
\end{tabular}

\section{CONCLUSION}

The present study conclude that it is a simple procedure for biofabrication of silver nanoparticles with several advantages such as cost-effectiveness, compatibility for biomedical and pharmaceutical applications as well as for large-scale commercial production. The primary confirmatory for the silver nanoparticles were colour changes and UV-vis adsorption spectra of silver nanoparticles formed peak at $417 \mathrm{~nm}$. FTIR spectra confirmed that bio molecules such as jasminol, alkaloids, triterpinoids act as reducing and capping agents for biosynthesis of silver nanoparticles. The XRD analysis revealed that the silver nanoparticles are a highly crystalline fcc geometry with a 15-20 nm in size. The SEM image showed that the stable silver nanoparticles are in rod, spherical, triangle and hexagonal shapes. The green synthesized silver nanoparticles have more effective antibacterial activity to the pathogens. The present study emphasizes the use of medicinal plants for synthesis of silver nanoparticles with high potent antibacterial effect. This study offers use of jasminum auriculatum leaf as new crop for synthesis of inorganic materials (nanoparticles) with potential future pharmaceutical and biomedical applications in worldwide.

\section{ACKNOWLEDGEMENTS}

The authors are thankful to Dr. A.R. Anub, chairman, A.R. College of Engineering \& Technology, Kadayam, India for providing lab facilities. Authors are also thankful to International Research Centre, Kalasalingam University, Krishnankoil, India for providing the XRD facility and the SEM with EDX facilities. 


\section{REFERENCES}

[1] Virender K. Sharma, Ria A. Yngard, Yekaterina Lin, Silver nanoparticles: Green synthesis and their antimicrobial activities, Advances in Colloid and Interface Science 145(2009) 83-96.

[2] Matteo Crosera, Massimo Bovenzi, Giovanni Maina, Gianpiero Adami, Caterina Zanette, Chiara Florio, Francesca Filon Larese, Nanoparticle dermal absorption and toxicity: a review of the literature, International Archives of Occupational and Environmental Health 82(9) (2009) 1043-1055.

[3] Fendler JH, Tian Y, Nanoparticles and nanostructured films: preparation, characterization and applications., John Wiley \& Son ,1998, pg: 429-461.

[4] Mehmood A, Ghulam M, Tariq MB, Rehana Kausar, Phyto-mediated synthesis of silver nanoparticles from Melia azedarach L. leaf extract: Characterization and antibacterial activity, Arabian Journal of Chemistry ( 2013) 1-6.

[5] Prakasha P, Gnanaprakasama P, Emmanuela R, Arokiyaraja S, Saravanan M, Green synthesis of silver nanoparticles from leaf extract of Mimusops elengi. Linn for enhanced antibacterial activity against multi drug resistant clinical isolates, colloids and surfaces B: Biointerface 108(2013) 255-259.

[6] Shankar S. S, Rai A, Ahmad A, Sastry M, Rapid synthesis of Au, Ag, and bimetallic Au core Ag shell nanoparticles using Neem (Azadirachta indica) leaf broth. J Colloid Interface 275(2) (2004) 496-502.

[7] Elumalai E. K, Prasad T. N, Hemachndran V. K, Viviyan Therasa J. S, Thirumalai T, David E, Extracellular synthesis of silver nanoparticles using leaves of Euphorbia hirta and their antimicrobial activities. Journal of Pharmaceutical Sciences and Research 2(9) (2010) 549554.

[8] Savitharamma N, Linga Rao M, Rukmini K, Suvrnalata Devi P, Antimicrobial activity of silver nanoparticles synthesized by using medicinal plants, International Journal of Chem Tech Research 3(3) (2011) 1394-1402.

[9] Shankar S.S, Ahmed A, Sastry M, Geranium leaf assisted biosynthesis of silver nanoparticles, Biotechnology Process 19(6) (2003) 1627-1631.

[10] Kohler .J.M, Hubner .U, Romanus .H, Wagner, Formation of star-like and core-shell AuAg nanoparticles during two and three step preparation in batch and microfluidic systems, J. Nanomat. 1155 (2007) 98134-98141.

[11] Southam .G, Beveridge .T.J, The in vitro formation of placer gold by bacteria, Geochim Cosmochim Acta 58(20) (1994) 4527-4530.

[12] Prasad .K, Jha .A.K, Kulkarni .A.R, Lactobacillus assisted synthesis of titanium nanoparticles, Nanoscale Res. Let. 2(5) (2007) 248-250.

[13] David D, Evanoff Jr, George Chumanov, Synthesis and Optical Properties of Silver Nanoparticles and Arrays, chemphysche 6(7) (2005) 1221-1231.

[14] Ohashi .S, Saku .S, Yamamoto .K, Antibacterial activity of silver inorganic agent YDA filler, Journal of Oral Rehabilitation 31( 4) (2004) 364-367.

[15] Jiang .H, Manolache .S,Wong .A.C.L, Denes .F.S, Plasma-enhanced deposition of silver nanoparticles onto polymer and metal surfaces for the generation of antimicrobial characteristics, Journal of Applied Polymer Science 93(3) (2004) 1411-1422 .

[16] Panacek A, Kvitek L, Prucek R, kolar M, Vecerova R, Pizurova N, K. Sharama V, Navecna T, Zboril R, Silver colloid nanoparticles synthesis characterization and their antibacterial activity, J Phys Chem B. 110 (33) (2006) 16248-16253. 
[17] http:// www.flowersofindia.net/catalog/slides/Juhi.html.

[18] http://apps.kew.org/wcsp/namedetail.do?name_id=351735

[19] http:/biodiversitylibrary.org/page/38535080

[20] Arun Mital, Satish Sardana, Anima Pandey, Jasminum Auriculatum-An Overview, International Journal Of Pharmaceutical Innovations 1(4) (2011) 30-35.

[21] Deshpande P.J, Shankaran P.S, Pathak S.N., The role of Jasminum auriculatum in experimental wound healing, Med. Surg. 5(1965) pg: 27.

[22] Bahuguna Y, Singh M, Rawat M, Juyal V, Gupta V., Antilithiatic effect of flowers of Jasminum auriculatum vahl., International Journal of Green Pharmacy 3(2) (2009) 155-158.

[23] Amit Gupta, Sushama R Chaphalkar, Use Of Flow Cytometry To Measure The Immunostimulatory Activity Of Aqueous Extract Of Jasminum Auriculatum, International Journal of Current Advanced Research 4(5) (2015) 87-91.

[24] Balasubramanian.S. , Jeyapaul.U ,John Bosco.A, Mary Jelastin Kala.S , Green Synthesis of Silver Nanoparticles Using Cressa Cretica Leaf Extract and its antibacterial efficacy, International Journal of Advanced Chemical Science and Applications 3(1) (2015) 65-71.

[25] Bauer AW, Kirby WMM, Sherris JC, Truck M , Am. J. Clin. Pathol.45(2) (1966) pg:493

[26] Mangrola M.H., Joshi V. G., Dudhagura P. R., Parmar B. H., Two step synthesis and biophysical characterization of silver nanoparticles using green approach, J. Environ. Res. Develop. 7(2A) (2012) 1021-1025.

[27] Ghadiyali Tejaskumar R , Kayasth Manish M , Contribution of green technology in sustainable development of agriculture sector, J. Environ. Res. Develop.7(1A) (2012) 590-596.

[28] Mona Safaepour, Ahmad Reza Shahverdi, Hamid Reza Shahverdi, Mohammad Reza Khorramizadeh, Ahmad Reza Gohari, Green synthesis of small silver nanoparticles using Geraniol and its cytotoxicity against Fibrosarcoma-wehi 164 , Avicenna J Med Biotech. 1(2) (2009) 111-115.

[29] Irsad,A.Wani, Aparna Ganguly, Jahangeer Ahmed, Tokeer Ahmed, Silver Nanoparticles: Ultrasonic wave assisted synthesis, optical characterization surface area studies, Mat. Lett. 65(3) (2011) 520-522.

[30] Rajeshkumar S., Malarkodi C., Paulkumar K., Vanaja M., Gnanajobitha G., Annadurai G., Intracellular and extracellular biosynthesis of silver nanoparticles by using marine bacteria Vibrio alginolyticus, Nanoscience and Nanotechnology: An International Journal 3(1) (2013) 21-25.

[31] Jeyapaul.U, Parvathikrishnan.S, John Bosco. A, Balasubramanian.S, Mary Jelastin Kala.S , Biosynthesis of Silver Nanoparticles Using Triumfetta Rhomboidea Leaf Extract and the antibacterial efficacy, International Journal of Advanced Chemical Science and Applications 3(1) (2015) 17-20.

[32] Anandh.B, Muthuvel.A, Emayavaramban.M, Biosynthesis and characterization of silver nanoparticles using Lagenaria siceraria leaf extract and their antibacterial activity, International letters of chemistry, physics and astronomy 38 (2014) 35-45. 